\title{
Dietary Ganglioside Reduces Proinflammatory Signaling in the Intestine
}

\author{
John Janez Miklavcic, ${ }^{1}$ Kareena Leanne Schnabl, ${ }^{2}$ Vera Christine Mazurak, ${ }^{1}$ \\ Alan Bryan Robert Thomson, ${ }^{3}$ and Michael Thomas Clandinin ${ }^{1}$ \\ ${ }^{1}$ 4-002 Li Ka Shing Centre for Health Research Innovation, University of Alberta, Edmonton, AB, Canada T6G 2R1 \\ ${ }^{2}$ 200, 10150-102 street, Dyna LIFE Diagnostics, Edmonton, AB, Canada T5J 5E2 \\ ${ }^{3}$ Division of Gastroenterology, University of Western Ontario, London, ON, Canada N6A 5A5
}

Correspondence should be addressed to Michael Thomas Clandinin, tclandin@professorpufa.com

Received 9 August 2011; Revised 7 October 2011; Accepted 7 October 2011

Academic Editor: Phillip B. Hylemon

Copyright (c) 2012 John Janez Miklavcic et al. This is an open access article distributed under the Creative Commons Attribution License, which permits unrestricted use, distribution, and reproduction in any medium, provided the original work is properly cited.

\begin{abstract}
Gangliosides are integral to the structure and function of cell membranes. Ganglioside composition of the intestinal brush border and apical surface of the colon influences numerous cell processes including microbial attachment, cell division, differentiation, and signaling. Accelerated catabolism of ganglioside in intestinal disease results in increased proinflammatory signaling. Restoring proper structure and function to the diseased intestine can resolve inflammation, increase resistance to infection, and improve gut integrity to induce remission of conditions like necrotizing enterocolitis (NEC) and Crohn's disease (CD). Maintaining inactive state of disease may be achieved by reducing the rate that gangliosides are degraded or by increasing intake of dietary ganglioside. Collectively, the studies outlined in this paper indicate that the amount of gangliosides GM3 and GD3 in intestinal mucosa is decreased with inflammation, low level of GM3 is associated with higher production of proinflammatory signals, and ganglioside content of intestinal mucosa can be increased by dietary ganglioside.
\end{abstract}

\section{Review}

Ganglioside refers to a network of sialylated glycosphingolipids, each with independent biologic properties (Figure 1) [1-3]. Gangliosides are found mainly in the lipid rafts of the intestinal mucosa [4]. Gangliosides consist of a charged, hydrophilic region that protrudes from the membrane surface, and a hydrophobic ceramide anchored in the cell membrane [5].

1.1. Ganglioside Synthesis and Degradation. In mammalian cells, ganglioside synthesis commences with ceramide synthesis in the endoplasmic reticulum $[7,8]$. Ceramide is transported to the cytosolic Golgi face for addition of glucose [9]. From this point, sugar moieties and sialic acids are added to form one of several gangliosides. These reactions are accomplished by sialyltransferases, galactosaminyltransferases, and galactosyltransferases on the luminal face of the Golgi complex at controlled rates [10]. Ganglioside catabolism is outlined in Figure 2.
1.2. Ganglioside Content and Composition. The amount and content of ganglioside varies among species and in tissues within species [12]. Transcriptional and posttranslational events regulate the amount and content of ganglioside in cells [13]. Ganglioside content is particularly high in the central nervous system, relative to other tissues of the body [14]. The fatty acid tail of ceramide also varies in length within gangliosides [15], as demonstrated in A2780 ovarian carcinoma cells [16]. Variability in sialic acid configuration, oligosaccharide size, and length of ceramide may have consequences that alter ganglioside localization and functionality [17-19]. It is unknown whether many of the health benefits attributed to gangliosides are due to a specific ganglioside species like GM3 or GD3, or whether the fatty acid component of the ceramide tail alters the molecular role of the ganglioside.

\section{Ganglioside in Diet}

In addition to endogenous ganglioside biosynthesis, ganglioside can also be obtained exogenously from diet [20]. 


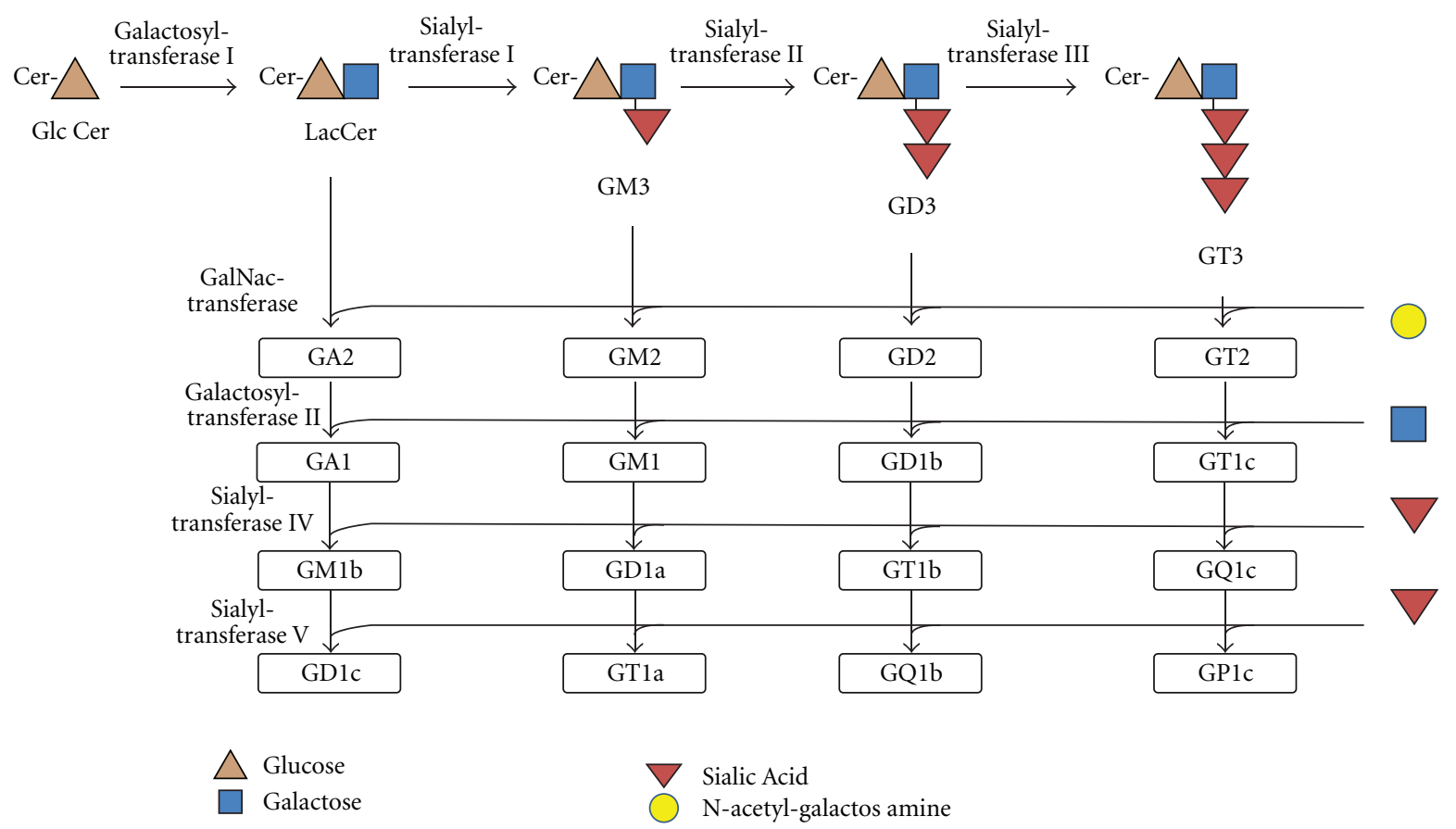

FIGURE 1: General scheme for ganglioside synthesis. Network of ganglioside synthesis; steps are also reversible. "G" denotes "ganglioside;" "A" denotes "asialo" or lacking sialic acid; "M" denotes "monosicalo," "D" denotes "disialo;" numbers denote carbohydrate sequence. Adapted from Malisan and Testi [6]. Cer: ceramide; GlcCer: glucosylceramide; LacCer: lactosylceramide; GalNac: N-acetylgalactosamine.

GM1

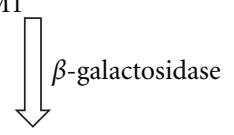

GM2

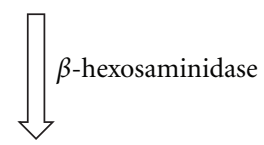

GD3 $\underset{\text { Sialidase }}{\rightleftharpoons}$

GM3 $\underset{\text { Sialidase }}{\longrightarrow}$ Lactosylceramide Glucosylceramide

$\beta$-glucosidase

FIGURE 2: Ganglioside catabolism. Enzyme responsible for catabolic processing step is shown adjacent to arrow. Adapted from Devlin [11].

The milk fat globule membrane is a biological membrane enriched in ganglioside that protects and stabilizes milk fat in the aqueous phase [21]. Dietary ganglioside intake is very low unless consuming whole-organ foods (i.e., brain), whole milk, buttermilk, or colostrum in high quantities. Several tissues have been shown to incorporate dietary gangliosides. Caco-2 cells incorporate GD3 [22] when provided with ganglioside in vitro [23]. Ganglioside uptake also occurs in several tissues in vivo. Providing ganglioside in the diet increases ganglioside content in intestinal mucosa [20]. Providing GM3 and GD3 in the diet increased total ganglioside content of epithelial cells within intestine and retina in rats $[20,24]$. The estimated average intake of ganglioside in a healthy population is well below levels believed to bear therapeutic benefit [25].
2.1. Fates of Dietary Ganglioside. GD3 is specifically localized to the basolateral membrane surface, while GM3 is localized at the brush border membrane of the enterocyte [26]. According to Pagano's vesicle sorting theory [27], absorbed gangliosides have three fates: transport back to the plasma membrane immediately after being endocytosed; endocytosis to the Golgi apparatus for glycosylation to form more complex ganglioside species; transport by the endosome to the lysosome for degradation. Metabolic kinetics of GD3 has been described in depth in Caco-2 cells. GD3 taken up by the brush border membrane is mainly metabolized into new ganglioside species, with smaller portions being retained or transferred, whereas GD3 taken up by the basolateral membrane is not retained or transferred to any significant degree [22]. These observations suggest that each species of 
ganglioside localizes to particular regions of the enterocyte to carry out specific functions, which depend on site of uptake. There is a gap in understanding of how ganglioside uptake by different cell types and regions of the gut is regulated.

2.2. Ganglioside in Intestinal Health. Important observations from animal studies show that inflamed intestinal mucosa has less ganglioside content than healthy intestinal mucosa [28]. Dietary ganglioside is able to replace mucosal gangliosides that are continually degraded in inflammatory states. Moreover, increasing ganglioside content through diet decreases proinflammatory cytokine production in intestinal mucosa $[24,28]$ and prevents hypoxia-induced bowel necrosis and cell injury in cultured infant bowel [29]. The following section summarizes the different modes of action by which dietary gangliosides promote intestinal health.

\section{Mechanisms of Action of Ganglioside}

3.1. Gut Integrity. Previous studies indicate that ganglioside prevents proinflammatory stimuli from disrupting integrity of tight junctions between enterocytes. Feeding ganglioside to rats prevented a lipopolysaccharide- (LPS-) stimulated decrease in cellular tight junction protein occludin [30]. This work indicates that low levels of GM3 in the intestinal mucosa are associated with degradation of tight junction proteins. Improving intestinal integrity is important for management of diarrhea, infection, penetration of allergens, and malnutrition. Guanylate-binding protein-1 (GBP-1) has been recently identified as a marker of intestinal integrity. Downregulation of GBP-1 has been reported to increase permeability and apoptosis of intestinal cells [31]. The effect of ganglioside on GBP-1 stability is currently unknown and is of interest as a potential therapeutic target.

3.2. Immune Cell Targeting. Chemokine receptor type 9 (CCR9) enables immune cells to target the gut [32]. While CCR9-positive immune cells are found mainly in small intestine, integrin $\alpha_{4} \beta_{7}$-positive cells tend to home to both small intestine and colon [33]. Integrin-mediated binding may be indirectly influenced by ganglioside. In the plasma membrane, gangliosides are known to localize with proteins which bear specific amino acid sequences [34]. GD3 has been shown to cluster with $\beta_{1}$ integrin and affect properties controlled by integrin-mediated signalling [35]. The interactions between gangliosides and integrins have not received much attention, but may provide important insights into homing of immune cells to gut in conditions like inflammatory bowel disease (IBD).

3.3. Immune Cell Signaling. Gangliosides are organized into microdomains termed lipid rafts that float freely in the lipid bilayer [36] and serve as organizing centers for assembly of signaling molecules and receptor trafficking [37, 38]. Organization of signaling molecules into lipid rafts is vital for regulation of T-lymphocyte activation pathways that play a major role in pathology of IBD [39, 40]. Disruption of lipid rafts displaces cellular signaling molecules and alters immunoreceptor signal transduction [41-43]. Specifically, sphingolipid depletion inhibits glycophosphatidylinositolanchored protein trafficking in microdomains [44]. Absence or increased catabolism of ganglioside adversely affects lipid raft trafficking and signaling functions and promotes an inflammatory environment. Gangliosides are imperative for proper structure and function of lipid rafts and dietary ganglioside may disrupt constitutive activation of inflammatory pathways that are hallmark of intestinal disease.

\subsection{Proinflammatory Mediators. Inflammation characterizes} several chronic diseases including cardiovascular disease, cancer, NEC, and IBD. In culture, inflamed intestinal mucosa has significantly decreased ganglioside content [28]. Changes in ganglioside content and composition also occur in the oncogenic transformation of tissue. Undifferentiated Caco2 cells have lower total GD3 and polar gangliosides than differentiated Caco-2 model intestinal epithelial cells [45]. It is unknown whether ganglioside catabolism precedes the proinflammatory signals and subsequent inflamed state, or whether inflammation induces ganglioside catabolism. Enrichment of intestinal mucosa with ganglioside causes a reduction in cholesterol content [28]. Cholesterol depletion disrupts membrane microdomain structure and inhibits generation of proinflammatory mediators [46, 47]. In preclinical studies, ganglioside treatment increases ganglioside content and inhibits signals caused by proinflammatory stimuli tumour necrosis factor- $\alpha$ and interleukin- (IL-) $1 \beta$ in rats [28]. Similarly, ganglioside reduces IL-6 and IL-8 production in cultured infant bowel when exposed to LPS under hypoxic conditions [29]. Replacing ganglioside that is degraded protects the gut by attenuating proinflammatory signals.

3.5. Anti-Inflammatory Mediators. Previous studies have shown enhanced production of IL-10 with dietary ganglioside treatment [30]. IL-10 is an anti-inflammatory cytokine and may be involved in resolution of inflammation. Polyunsaturated docosahexaenoic-acid-derived resolvins and protectins have recently been discovered as having antiinflammatory properties [48]. Production of resolvin D3 and protectin 1/D1 may be responsible for blocking dextran sodium sulfate-induced colitis in mice [49]. Therefore, resolvins and protectins have been suggested as novel candidates for IBD therapy [50]. Ganglioside in the diet increases the amount of polyunsaturated fat relative to saturated fat in weanling rat intestine [51] and, thus, may enable enhanced production of resolvins and protectins.

3.6. Prevention of Infection. Provision of dietary ganglioside known to have antibacterial properties increases the resistance of an individual to negative effects of microbial pathogens. Evidence suggests that patients with IBD may be more prone to infection than healthy individuals [52]. In a Spanish population, mutation in authophagy related 16-like 1 (ATG16L1) is associated with prevalence of CD [53]. ATG16L1 is part of a group of proteins involved in autophagy [54]. Defects in ATG16L1 may allow for 


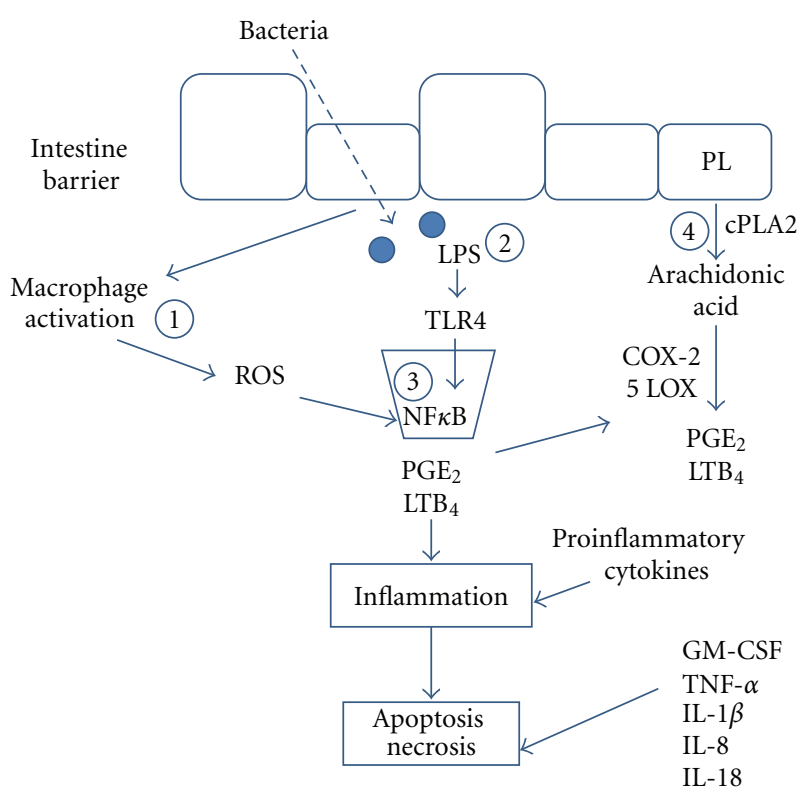

Figure 3: Inflammatory signaling cascade and mechanisms by which ganglioside protects the intestine from inflammation and injury. There are at least four possible mechanisms by which ganglioside protects intestine from injury: (1) gangliosides prevent proliferation, maturation and targeting of immune cells; (2) gangliosides bind enterotoxic LPS and prevent interaction with TLR4; (3) gangliosides inhibit $\mathrm{NF} \kappa \mathrm{B}$ activation; and (4) gangliosides prevent production of $\mathrm{LTB}_{4}$ and $\mathrm{PGE}_{2}$. Adapted from Schnabl et al. [29]. COX-2 = cyclooxygenase-2; cPLA2 = cytosolic phospholipase A2; $\mathrm{LTB}_{4}=$ leukotriene $\mathrm{B}_{4}$; LPS = lipopolysaccharide; 5 LOX = 5 lipoxygenase; $\mathrm{PGE}_{2}=$ prostaglandin $\mathrm{E}_{2} ; \mathrm{PL}=$ phospholipid; $\mathrm{ROS}=$ reactive oxygen species; $1,2,3,4=$ steps inhibited by ganglioside; TLR4 $=$ toll-like receptor -4 .

infectious organisms to persist, triggering an exacerbated immune response in the gut. Toll-like receptor-4 (TLR4) was found to be higher in intestinal mucosa of children with IBD than healthy controls [55]. Upon stimulation of TLR4 by pathogens or enterotoxins (Figure 3), immune cells produce reactive oxygen species that lead to activation of nuclear transcription factor-kappaB $(\mathrm{NF} \kappa \mathrm{B})$ pathway and production of inflammatory mediators. Ganglioside inhibits binding, toxin production, and infectivity of several intestinal pathogens $[56,57]$, thereby attenuating $\mathrm{NF} \kappa \mathrm{B}$ inflammatory signaling pathways. Ganglioside may play a critical role in supporting gut health by preventing secondary infection and the associated inflammatory signaling cascade.

3.7. NFאB Pathway. CARD15 (nucleotide-oligomerization domain-containing protein 2 (NOD2)) polymorphism has most consistently arisen as a genetic risk factor for $\mathrm{CD}$ $[58,59]$. The normal function of CARD15 is to suppress $\mathrm{NF} \kappa \mathrm{B}$ stimulation [60]. Defects in CARD15 allow constitutive activation of $\mathrm{NF} \kappa \mathrm{B}$, resulting in chronic inflammation and injury to intestinal mucosa. Nucleotide-oligomerization domain-containing protein 1 (NOD1) is an activator of $\mathrm{NF} \kappa \mathrm{B}$ and wild-type NOD1 is associated with increased risk of $\mathrm{CD}$ [61]. Ganglioside may attenuate $\mathrm{NF} \kappa \mathrm{B}$ signaling as a previous study showed that GD3 prevented activation of $\mathrm{NF} \kappa \mathrm{B}$ in mitogen-stimulated T cells [62]. This is particularly important since cyclooxygenase (COX) and lipoxygenase (LOX) enzyme production is increased by stimulation of $\mathrm{NF} \kappa \mathrm{B}$ pathway [63]. COX and LOX metabolize arachidonic acid (AA) into proinflammatory mediators leukotriene $\mathrm{B}_{4}$ $\left(\mathrm{LTB}_{4}\right)$ and prostaglandin $\mathrm{E}_{2}\left(\mathrm{PGE}_{2}\right)$. It has been shown that ganglioside prevents production of $\mathrm{LTB}_{4}$ and $\mathrm{PGE}_{2}$ in infant bowel when cultured with LPS [29]. Ganglioside appears to inhibit production of $\mathrm{LTB}_{4}$ and $\mathrm{PGE}_{2}$ in intestine by blocking nuclear translocation of $\mathrm{NF} \kappa \mathrm{B}$ [64].

\section{IBD Background}

Ganglioside has shown therapeutic benefit in models of proinflammatory diseases that have common features with IBD. Collectively known as IBD, CD and ulcerative colitis (UC) severely impede quality of life in afflicted individuals. IBD presents with abdominal pain, gastrointestinal bleeding, diarrhea, weight loss, and malnutrition; all of which negatively impact social and emotional welfare. IBD can be associated with development of joint, liver, and kidney diseases, and an elevated risk of lymphoma and colorectal cancer. Disease management is difficult and may consist of costly drug treatment including steroids, immunosuppressants [65], or antibiotics [66]. Some individuals with IBD do not respond to standard drug treatment, while others experience negative or toxic adverse effects [67]. Administration of prednisolone has been shown as a risk factor for development osteoporosis in older patients with IBD [68]. Severe cases require surgery to remove the affected bowel, and psychological factors including stress may trigger disease flares [69]. The etiologies of CD and UC are poorly understood and there is no cure for IBD.

4.1. IBD Epidemiology. At a rate of $0.60 \%$ of the population [70], prevalence of IBD is particularly high in Canada [71] compared to the rest of the world [72-74]. Prevalence of IBD is also high in the United States, where reported incidence is approximately 1.1 million people per year [72]. IBD is a considerable economic burden. In 2008, economic cost per patient with IBD was estimated above $\$ 9,000 /$ year in Canada [70]. Another study reported direct healthcare costs greater than $\$ 18,000 /$ patient-year in the United States [75]. There is a clear need for knowledge of disease mechanisms to develop novel cost-effective treatment strategies for sustained remission of disease.

4.2. IBD Pathology. CD is chronic enteritis that can occur at any site along the gastrointestinal tract. Initial lesions are characterized by tiny mucosal defects termed aphthous ulcers [76]. There is an infiltration of macrophages that release proinflammatory mediators and perpetuate the inflammatory process. This process contributes to development of fibrotic bands and granulomas. Ulcers grow in size and, as submusoca thickens, fistulae may develop. While inflammation associated with CD occurs in a transmural fashion in the colonic wall, UC-associated inflammation 
is present superficially at the level of mucosa [77]. With respect to immune system involvement, UC is characterized by $T_{h} 1$ cells and $C D$ by $T_{h} 2, T_{h} 17$, and cells involved in innate immunity. There is a strong genetic component that contributes to IBD risk, particularly CD [78]. While a number of genes have been linked to aspects of IBD, environment also plays a large role in active disease. IBD rates are very high in industrialized countries like Canada and the USA. Studies have linked urban environment, smoking, diet high in sugar or total fat, antibiotic use in childhood, nonsteroidal anti-inflammatory use, and many other factors to IBD risk [79]. IBD is a multifactorial disorder of complex origin that appears to stem from changes initially occurring at the cell membrane.

4.3. Ganglioside in IBD Pathology. Ganglioside species compositions differ among several disease states. For example, Sandhoff's, Gaucher, and Tay Sach's diseases are characterized by abnormal sphingolipid metabolism due to gene deficiencies for catabolic enzymes and accumulation of gangliosides [80]. A few studies have delved into the relationship between genes that regulate ganglioside metabolism and IBD. A genetic variant of lysosomal sialidase is associated with CD [81], but this study did not assess whether ganglioside content correlates with sialidase genotype. Another study showed that there was no difference in $\beta$-galactosidase enzyme activity between LPS-stimulated mononuclear cells from IBD patients and healthy controls [82]. In the same study, $\beta$-hexosaminidase enzyme activity was higher in peripheral blood monocytes of patients with IBD than in healthy control subjects when incubated with LPS. Since $\beta$-hexosaminidase generates GM3 from GM2, accelerated ganglioside catabolism contributes to pathogenesis of IBD.

\section{Conclusions}

IBD is a disorder influenced by many environmental and genetic factors. Signs regularly present in individuals with IBD include chronic inflammation, overactive immune response, and impaired integrity and permeability of gut. While signs and symptoms may subside for short periods of time, recurrence of IBD-related episodes is regular. There is appreciable cost associated with treating IBD. As surgical intervention or drug administration does not result in a cure, there is demand for new treatment initiatives. Emerging evidence shows the critical role of ganglioside in supporting intestinal health. Ganglioside metabolism in the intestinal mucosa is fundamental to the etiology of IBD. Studies show that low levels of ganglioside in the intestinal mucosa are associated with increased levels of inflammatory markers, susceptibility to pathogens, and poor gut integrity. Dietary ganglioside constitutes an exciting new therapeutic agent which targets intestinal cells and associated immune surveillance by interrupting the inflammatory cascade and subsequently alleviating signs and symptoms of inflammatory intestinal diseases. Dietary ganglioside consumption alleviates many of the burdensome processes in models of intestinal disease that are also characteristic of IBD and, thus, may provide benefit to afflicted individuals.

\section{Abbreviations}

$\begin{array}{ll}\text { AA: } & \text { Arachidonic acid } \\ \text { ATG16L1: } & \text { Autophagy-related 16-like 1 } \\ \text { CCR9: } & \text { Chemokine receptor type } 9 \\ \text { CD: } & \text { Crohn's disease } \\ \text { COX: } & \text { Cyclooxygenase } \\ \text { GBP-1: } & \text { Guanylate-binding protein-1 } \\ \text { IBD: } & \text { Inflammatory bowel disease } \\ \text { IL: } & \text { Interleukin } \\ \text { LTB } 4: & \text { Leukotriene } \text { B }_{4} \\ \text { LOX: } & \text { Lipoxygenase } \\ \text { NEC: } & \text { Necrotizing enterocolitis } \\ \text { NF } \kappa \text { B : } & \text { Nuclear transcription factor kappaB } \\ \text { NOD1: } & \text { Nucleotide-binding oligomerization } \\ & \text { domain-containing protein } 1 \\ \text { NOD2: } & \text { Nucleotide-binding oligomerization } \\ & \text { domain-containing protein } 2 \\ \text { PGE } 2: & \text { Prostaglandin } E_{2} \\ \text { TLR4: } & \text { Toll-like receptor-4 } \\ \text { UC: } & \text { Ulcerative colitis. }\end{array}$

\section{Conflict of Interests}

The authors declare that they have no conflict of interests.

\section{Authors' Contributions}

J. J. Miklavcic, K. L. Schnabl, V. C. Mazurak, A. B. R. Thomson, and M. T. Clandinin were fundamental in drafting the paper. All authors read and approved the final paper.

\section{Acknowledgments}

The authors would like to acknowledge personal and research funding sources. J. J. Miklavcic is funded by AFNS PhD Scholarship and MITACS Accelerate. V. C. Mazrak and M. T. Candinin are funded by Canadian Institutes of Health Research.

\section{References}

[1] J. Nakano, H. Yasui, K. O. Lloyd, and M. Muto, "Biologic roles of gangliosides G(M3) and G(D3) in the attachment of human melanoma cells to extracellular matrix proteins," Journal of Investigative Dermatology Symposium Proceedings, vol. 4, no. 2, pp. 173-176, 1999.

[2] X. Q. Wang, Q. Yan, P. Sun et al., "Suppression of epidermal growth factor receptor signaling by protein kinase $\mathrm{C}-\alpha$ activation requires CD82, caveolin-1, and ganglioside," Cancer Research, vol. 67, no. 20, pp. 9986-9995, 2007.

[3] S. Ohkubo and N. Nakahata, "The role of lipid rafts in trimeric G protein-mediated signal transduction," Yakugaku Zasshi, vol. 127, no. 1, pp. 27-40, 2007.

[4] K. A. Vyas, H. V. Patel, A. A. Vyas, and R. L. Schnaar, "Segregation of gangliosides GM1 and GD3 on cell membranes, isolated membrane rafts, and defined supported lipid monolayers," Biological Chemistry, vol. 382, no. 2, pp. 241250, 2001. 
[5] L. A. Drozdowski, M. T. Clandinin, and A. B. Thomson, "Morphological, kinetic, membrane biochemical and genetic aspects of intestinal enteroplasticity," World Journal of Gastroenterology, vol. 15, no. 7, pp. 774-787, 2009.

[6] F. Malisan and R. Testi, "GD3 ganglioside and apoptosis," Biochimica et Biophysica Acta, vol. 1585, no. 2-3, pp. 179-187, 2002.

[7] M. Fukasawa, M. Nishijima, and K. Hanada, "Genetic evidence for ATP-dependent endoplasmic reticulum-to-Golgi apparatus trafficking of ceramide for sphingomyelin synthesis in Chinese hamster ovary cells," Journal of Cell Biology, vol. 144, no. 4, pp. 673-685, 1999.

[8] S. Yasuda, H. Kitagawa, M. Ueno et al., "A novel inhibitor of ceramide trafficking from the endoplasmic reticulum to the site of sphingomyelin synthesis," Journal of Biological Chemistry, vol. 276, no. 47, pp. 43994-44002, 2001.

[9] T. Kolter, R. L. Proia, and K. Sandhoff, "Combinatorial ganglioside biosynthesis," Journal of Biological Chemistry, vol. 277, no. 29, pp. 25859-25862, 2002.

[10] S. Birklé, G. Zeng, L. Gao, R. K. Yu, and J. Aubry, "Role of tumor-associated gangliosides in cancer progression," Biochimie, vol. 85, no. 3-4, pp. 455-463, 2003.

[11] T. M. Devlin, Ed., Textbook of Biochemistry with Clinical Correlations, Wiley Liss, New York, NY, USA, 3rd edition, 1992.

[12] M. Iwamori, J. Shimomura, S. Tsuyuhara, and Y. Nagai, "Gangliosides of various rat tissues: distribution of ganglio$\mathrm{N}$-tetraose-containing gangliosides and tissue-characteristic composition of gangliosides," Journal of Biochemistry, vol. 95, no. 3, pp. 761-770, 1984.

[13] E. Bieberich, "Integration of glycosphingolipid metabolism and cell-fate decisions in cancer and stem cells: review and hypothesis," Glycoconjugate Journal, vol. 21, no. 6, pp. 315327, 2004.

[14] R. Ledeen, "The chemistry of gangliosides: a review," Journal of the American Oil Chemists Society, vol. 43, no. 2, pp. 57-66, 1966.

[15] L. K. Sorensen, "A liquid chromatography/tandem mass spectrometric approach for the determination of gangliosides GD3 and GM3 in bovine milk and infant formulae," Rapid Communications in Mass Spectrometry, vol. 20, no. 24, pp. 3625-3633, 2006.

[16] A. Prinetti, L. Basso, V. Appierto et al., "Altered sphingolipid metabolism in $\mathrm{N}$-(4-hydroxyphenyl)-retinamideresistant A2780 human ovarian carcinoma cells," Journal of Biological Chemistry, vol. 278, no. 8, pp. 5574-5583, 2003.

[17] J. Müthing, U. Maurer, U. Neumann, B. Kniep, and S. Weber-Schürholz, "Glycosphingolipids of skeletal muscle: I. Subcellular distribution of neutral glycosphingolipids and gangliosides in rabbit skeletal muscle," Carbohydrate Research, vol. 307, no. 1-2, pp. 135-145, 1998.

[18] J. Müthing, U. Maurer, and S. Weber-Schürholz, "Glycosphingolipids of skeletal muscle: II. Modulation of $\mathrm{Ca}^{2+}$-flux in triad membranes by gangliosides," Carbohydrate Research, vol. 307, no. 1-2, pp. 147-157, 1998.

[19] S. Chiantia, J. Ries, G. Chwastek et al., "Role of ceramide in membrane protein organization investigated by combined AFM and FCS," Biochimica et Biophysica Acta, vol. 1778, no. 5, pp. 1356-1364, 2008.

[20] E. J. Park, M. Suh, and M. T. Clandinin, "Dietary ganglioside and long-chain polyunsaturated fatty acids increase ganglioside GD3 content and alter the phospholipid profile in neonatal rat retina," Investigative Ophthalmology and Visual Science, vol. 46, no. 7, pp. 2571-2575, 2005.
[21] C. Vanderghem, P. Bodson, S. Danthine, M. Paquot, C. Deroanne, and C. Blecker, "Milk fat globule membrane and buttermilks: from composition to valorization," Biotechnology, Agronomy and Society and Environment, vol. 14, no. 3, pp. 485$500,2010$.

[22] K. L. Schnabl, M. Larcelet, A. B. R. Thomson, and M. T. Clandinin, "Uptake and fate of ganglioside GD3 in human intestinal Caco-2 cells," American Journal of PhysiologyGastrointestinal and Liver Physiology, vol. 297, no. 1, pp. G52G59, 2009.

[23] L. Bode, C. Beermann, M. Mank, G. Kohn, and G. Boehm, "Human and bovine milk gangliosides differ in their fatty acid composition," Journal of Nutrition, vol. 134, no. 11, pp. 30163020, 2004.

[24] E. J. Park, M. Suh, B. Thomson, A. B. R. Thomson, K. S. Ramanujam, and M. T. Clandinin, "Dietary ganglioside decreases cholesterol content, caveolin expression and inflammatory mediators in rat intestinal microdomains," Glycobiology, vol. 15, no. 10, pp. 935-942, 2005.

[25] P. H. Pham, T. L. Duffy, A. L. Dmytrash, V. W. Lien, A. B. Thomson, and M. T. Clandinin, "Estimate of dietary ganglioside intake in a group of healthy edmontonians based on selected foods," Journal of Food Composition and Analysis, vol. 24, no. 7, pp. 1032-1037, 2011.

[26] E. J. Park, M. Suh, K. Ramanujam, K. Steiner, D. Begg, and M. T. Clandinin, "Diet-induced changes in membrane gangliosides in rat intestinal mucosa, plasma and brain," Journal of Pediatric Gastroenterology and Nutrition, vol. 40, no. 4, pp. 487-495, 2005.

[27] R. E. Pagano, "Lipid traffic in eukaryotic cells: mechanisms for intracellular transport and organelle-specific enrichment of lipids," Current Opinion in Cell Biology, vol. 2, no. 4, pp. 652-663, 1990.

[28] E. J. Park, M. Suh, B. Thomson et al., "Dietary ganglioside inhibits acute inflammatory signals in intestinal mucosa and blood induced by systemic inflammation of Escherichia coli lipopolysaccharide," Shock, vol. 28, no. 1, pp. 112-117, 2007.

[29] K. L. Schnabl, B. Larsen, J. E. Van Aerde et al., "Gangliosides protect bowel in an infant model of necrotizing enterocolitis by suppressing proinflammatory signals," Journal of Pediatric Gastroenterology and Nutrition, vol. 49, no. 4, pp. 382-392, 2009.

[30] E. J. Park, A. B. Thomson, and M. T. Clandinin, "Protection of intestinal occludin tight junction protein by dietary gangliosides in lipopolysaccharide-induced acute inflammation," Journal of Pediatric Gastroenterology and Nutrition, vol. 50, no. 3, pp. 321-328, 2010.

[31] M. Schnoor, A. Betanzos, D. A. Weber, and C. A. Parkos, "Guanylate-binding protein-1 is expressed at tight junctions of intestinal epithelial cells in response to interferon- $\gamma$ and regulates barrier function through effects on apoptosis," Mucosal Immunology, vol. 2, no. 1, pp. 33-42, 2009.

[32] W. Agace, "Generation of gut-homing $\mathrm{T}$ cells and their localization to the small intestinal mucosa," Immunology Letters, vol. 128, no. 1, pp. 21-23, 2010.

[33] L. S. Rott, J. R. Rosé, D. Bass, M. B. Williams, H. B. Greenberg, and E. C. Butcher, "Expression of mucosal homing receptor $\alpha 4 \beta 7$ by circulating CD $4+$ cells with memory for intestinal rotavirus," Journal of Clinical Investigation, vol. 100, no. 5, pp. 1204-1208, 1997.

[34] D. A. Cheresh, R. Pytela, M. D. Pierschbacher, F. G. Klier, E. Ruoslahti, and R. A. Reisfeld, "An Arg-Gly-Asp-directed receptor on the surface of human melanoma cells exists in a divalent cation-dependent functional complex with the 
disialoganglioside GD2," Journal of Cell Biology, vol. 105, no. 3, pp. 1163-1173, 1987.

[35] Y. Ohkawa, S. Miyazaki, M. Miyata, K. Hamamura, K. Furukawa, and K. Furukawa, "Essential roles of integrinmediated signaling for the enhancement of malignant properties of melanomas based on the expression of GD3," Biochemical and Biophysical Research Communications, vol. 373, no. 1, pp. 14-19, 2008.

[36] K. Simons and R. Ehehalt, "Cholesterol, lipid rafts, and disease," Journal of Clinical Investigation, vol. 110, no. 5, pp. 597-603, 2002.

[37] D. A. Brown and E. London, "Functions of lipid rafts in biological membranes," Annual Review of Cell and Developmental Biology, vol. 14, pp. 111-136, 1998.

[38] Z. Korade and A. K. Kenworthy, "Lipid rafts, cholesterol, and the brain," Neuropharmacology, vol. 55, no. 8, pp. 1265-1273, 2008.

[39] P. W. Janes, S. C. Ley, A. I. Magee, and P. S. Kabouridis, "The role of lipid rafts in T cell antigen receptor (TCR) signalling," Seminars in Immunology, vol. 12, no. 1, pp. 23-34, 2000.

[40] K. Simons and D. Toomre, "Lipid rafts and signal transduction," Nature Reviews Molecular Cell Biology, vol. 1, no. 1, pp. 31-39, 2000.

[41] P. S. Kabouridis, J. Janzen, A. L. Magee, and S. C. Ley, "Cholesterol depletion disrupts lipid rafts and modulates the activity of multiple signaling pathways in T lymphocytes," European Journal of Immunology, vol. 30, no. 3, pp. 954-963, 2000.

[42] P. S. Kabouridis, A. I. Magee, and S. C. Ley, "S-acylation of LCK protein tyrosine kinase is essential for its signalling function in T lymphocytes," EMBO Journal, vol. 16, no. 16, pp. 4983-4998, 1997.

[43] W. Zhang, R. P. Trible, and L. E. Samelson, "LAT palmitoylation: its essential role in membrane microdomain targeting and tyrosine phosphorylation during T cell activation," Immunity, vol. 9, no. 2, pp. 239-246, 1998.

[44] K. Kasahara and Y. Sanai, "Possible roles of glycosphingolipids in lipid rafts," Biophysical Chemistry, vol. 82, no. 2-3, pp. 121127, 1999.

[45] K. L. Schnabl, C. Field, and M. T. Clandinin, "Ganglioside composition of differentiated Caco-2 cells resembles human colostrum and neonatal rat intestine," British Journal of Nutrition, vol. 101, no. 5, pp. 694-700, 2009.

[46] B. U. Samuel, N. Mohandas, T. Harrison et al., "The role of cholesterol and glycosylphosphatidylinositol-anchored proteins of erythrocyte rafts in regulating raft protein content and malarial infection," Journal of Biological Chemistry, vol. 276, no. 31, pp. 29319-29329, 2001.

[47] A. A. Wolf, Y. Fujinaga, and W. I. Lencer, "Uncoupling of the cholera toxin-GM1 ganglioside receptor complex from endocytosis, retrograde golgi trafficking, and downstream signal transduction by depletion of membrane cholesterol," Journal of Biological Chemistry, vol. 277, no. 18, pp. 1624916256, 2002.

[48] C. N. Serhan, "Novel chemical mediators in the resolution of inflammation: resolvins and protectins," Anesthesiology Clinics of North America, vol. 24, no. 2, pp. 341-364, 2006.

[49] C. A. Hudert, K. H. Weylandt, Y. Lu et al., "Transgenic mice rich in endogenous omega-3 fatty acids are protected from colitis," Proceedings of the National Academy of Sciences of the United States of America, vol. 103, no. 30, pp. 11276-11281, 2006.

[50] K. H. Weylandt, J. X. Kang, B. Wiedenmann, and D. C. Baumgart, "Lipoxins and resolvins in inflammatory bowel disease," Inflammatory Bowel Diseases, vol. 13, no. 6, pp. 797799, 2007.

[51] E. J. Park, M. Suh, A. B. Thomson, K. S. Ramanujam, and M. T. Clandinin, "Dietary gangliosides increase the content and molecular percentage of ether phospholipids containing 20 : $4 n-6$ and $22: 6 n-3$ in weanling rat intestine," Journal of Nutritional Biochemistry, vol. 17, no. 5, pp. 337-344, 2006.

[52] J. F. Rodemann, E. R. Dubberke, K. A. Reske, D. H. Seo, and C. D. Stone, "Incidence of clostridium difficile infection in inflammatory bowel disease," Clinical Gastroenterology and Hepatology, vol. 5, no. 3, pp. 339-344, 2007.

[53] A. Marquez, C. Nunez, A. Martinez et al., "Role of ATG16L1 Thr300Ala polymorphism in inflammatory bowel disease: a study in the spanish population and a meta-analysis," Inflammatory Bowel Diseases, vol. 15, no. 11, pp. 1697-1704, 2009.

[54] R. Cooney and D. Jewell, "The genetic basis of inflammatory bowel disease," Digestive Diseases, vol. 27, no. 4, pp. 428-442, 2009.

[55] B. Szebeni, G. Veres, A. Dezsõfi et al., "Increased expression of Toll-like receptor (TLR) 2 and TLR4 in the colonic mucosa of children with inflammatory bowel disease," Clinical and Experimental Immunology, vol. 151, no. 1, pp. 34-41, 2008.

[56] A. Yagci, T. Yagci, B. Sener, Y. Suziki, and K. Ahmed, "Sulfatide mediates attachment of Pseudomonas aeruginosa to human pharyngeal epithelial cells," New Microbiologica, vol. 30, no. 2, pp. 167-171, 2007.

[57] F. Sanchez-Juanes, J. M. Alonso, L. Zancada, and P. Hueso, "Glycosphingolipids from bovine milk and milk fat globule membranes: a comparative study. Adhesion to enterotoxigenic Escherichia coli strains," Biological Chemistry, vol. 390, no. 1, pp. 31-40, 2009.

[58] R. K. Weersma, P. C. Stokkers, A. A. van Bodegraven et al., "Molecular prediction of disease risk and severity in a large Dutch Crohn's disease cohort," Gut, vol. 58, no. 3, pp. 388395, 2009.

[59] J. Sventoraityte, A. Zvirbliene, A. Franke et al., "NOD2, IL23R and ATG16L1 polymorphisms in Lithuanian patients with inflammatory bowel disease," World Journal of Gastroenterology, vol. 16, no. 3, pp. 359-364, 2010.

[60] T. Watanabe, A. Kitani, P. J. Murray, and W. Strober, "NOD2 is a negative regulator of Toll-like receptor 2-mediated T helper type 1 responses," Nature Immunology, vol. 5, no. 8, pp. 800808, 2004.

[61] F. Vasseur, B. Sendid, T. Jouault et al., "Variants of NOD1 and NOD2 genes display opposite associations with familial risk of crohn's disease and anti-saccharomyces cerevisiae antibody levels," Bowel Diseases. In press.

[62] D. N. Irani, K. L. Lin, and D. E. Griffin, "Brain-derived gangliosides regulate the cytokine production and proliferation ofactivated T cells," Journal of Immunology, vol. 157, no. 10, pp. 4333-4340, 1996.

[63] H. L. Pahl, "Activators and target genes of Rel/NF- $\kappa \mathrm{B}$ transcription factors," Oncogene, vol. 18, no. 49, pp. 6853-6866, 1999.

[64] A. Colell, C. García-Ruiz, J. Roman, A. Ballesta, and J. C. Fernández-Checa, "Ganglioside GD3 enhances apoptosis by suppressing the nuclear factor-kappa B-dependent survival pathway," The FASEB journal, vol. 15, no. 6, pp. 1068-1070, 2001.

[65] K. J. Khan, M. C. Dubinsky, A. C. Ford, T. A. Ullman, N. J. Talley, and P. Moayyedi, "Efficacy of immunosuppressive therapy for inflammatory bowel disease: a systematic review 
and meta-analysis," American Journal of Gastroenterology, vol. 106, no. 4, pp. 630-642, 2011.

[66] K. J. Khan, T. A. Ullman, A. C. Ford et al., "Antibiotic therapy in inflammatory bowel disease:a systematic review and metaanalysis," American Journal of Gastroenterology, vol. 106, no. 4, pp. 661-673, 2011.

[67] E. A. Maser, D. Deconda, S. Lichtiger, T. Ullman, D. H. Present, and A. Kornbluth, "Cyclosporine and infliximab as rescue therapy for each other in patients with steroid-refractory ulcerative colitis," Clinical Gastroenterology and Hepatology, vol. 6, no. 10, pp. 1112-1116, 2008.

[68] E. Tsironi, D. Hadjidakis, E. Mallas, C. Tzathas, D. G. Karamanolis, and S. D. Ladas, "Comparison of T- and Z-score in identifying risk factors of osteoporosis in inflammatory bowel disease patients," Journal of Musculoskeletal Neuronal Interactions, vol. 8, no. 1, pp. 79-84, 2008.

[69] C. N. Bernstein, S. Singh, L. A. Graff, J. R. Walker, N. Miller, and M. Cheang, "A prospective population-based study of triggers of symptomatic flares in IBD," American Journal of Gastroenterology, vol. 105, no. 9, pp. 1994-2002, 2010.

[70] Crohn's and Colitis Foundation of Canada Board, "The burden of inflammatory bowel disease (IBD) in canada," Tech. Rep., Crohn's and Colitis Foundation of Canada Board, Toronto, ON, Canada, 2008.

[71] C. N. Bernstein, A. Wajda, L. W. Svenson et al., "The epidemiology of inflammatory bowel disease in Canada: a populationbased study," American Journal of Gastroenterology, vol. 101, no. 7, pp. 1559-1568, 2006.

[72] C. G. Loftus, E. V. Loftus Jr, W. S. Harmsen et al., "Update on the incidence and prevalence of Crohn's disease and ulcerative colitis in Olmsted County, Minnesota, 1940-2000," Inflammatory Bowel Diseases, vol. 13, no. 3, pp. 254-261, 2007.

[73] S. Shivananda, J. Lennard-Jones, R. Logan et al., "Incidence of inflammatory bowel disease across Europe: is there a difference between north and south? results of the European collaborative study on inflammatory bowel disease (EC-IBD)," Gut, vol. 39, no. 5, pp. 690-697, 1996.

[74] R. B. Gearry, A. Richardson, C. M. A. Frampton et al., "High incidence of Crohn's disease in Canterbury, New Zealand: results of an epidemiologic study," Inflammatory Bowel Diseases, vol. 12, no. 10, pp. 936-943, 2006.

[75] A. P. Yu, L. A. Cabanilla, E. Q. Wu, P. M. Mulani, and J. Chao, "The costs of Crohn's disease in the United States and other Western countries: a systematic review," Current Medical Research and Opinion, vol. 24, no. 2, pp. 319-328, 2008.

[76] R. N. Fedorak and A. B. R. Thomson, "Inflammatory bowel disease," in First Principles of Gastroenterology, A. B. R. Thomson and E. A. Shaffer, Eds., pp. 326-372, AstraZeneca Canada, Mississauga, ON, Canada, 4th edition, 2000.

[77] R. K. Yantiss and R. D. Odze, "Diagnostic difficulties in inflammatory bowel disease pathology," Histopathology, vol. 48, no. 2, pp. 116-132, 2006.

[78] C. Abraham and J. H. Cho, "Inflammatory bowel disease," New England Journal of Medicine, vol. 361, no. 21, pp. 20662078, 2009.

[79] N. A. Molodecky and G. G. Kaplan, "Environmental risk factors for inflammatory bowel disease," Gastroenterology and Hepatology, vol. 6, no. 5, pp. 339-346, 2010.

[80] T. Kolter and K. Sandhoff, "Sphingolipid metabolism diseases," Biochimica et Biophysica Acta, vol. 1758, no. 12, pp. 2057-2079, 2006.
[81] C. M. Costello, N. Mah, R. Häsler et al., "Dissection of the inflammatory bowel disease transcriptome using genomewide cDNA microarrays," PLoS Medicine, vol. 2, no. 8, Article ID e199, 2005.

[82] N. Lugering, T. Kucharzik, H. Stein et al., "IL-10 synergizes with IL-4 and IL-13 in inhibiting lysosomal enzyme secretion by human monocytes and lamina propria mononuclear cells from patients with inflammatory bowel disease," Digestive Diseases and Sciences, vol. 43, no. 4, pp. 706-714, 1998. 


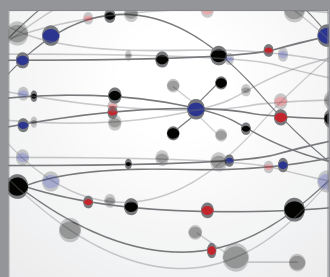

The Scientific World Journal
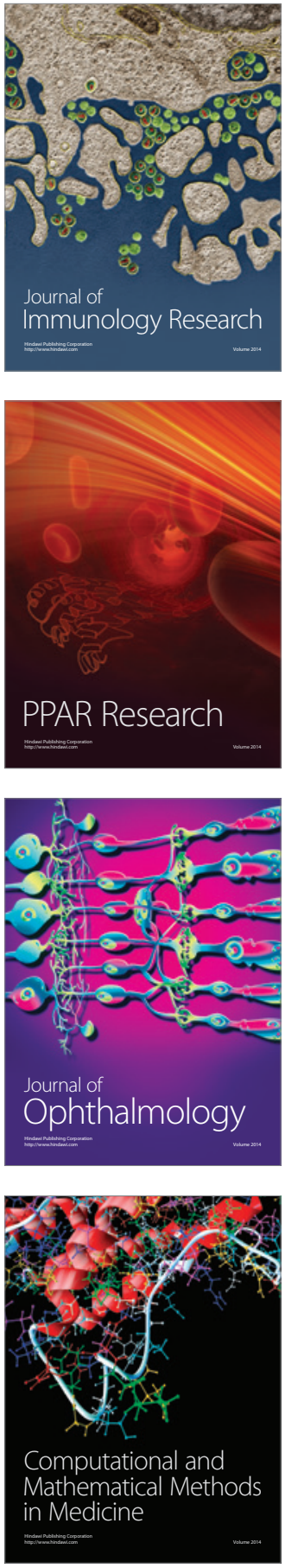

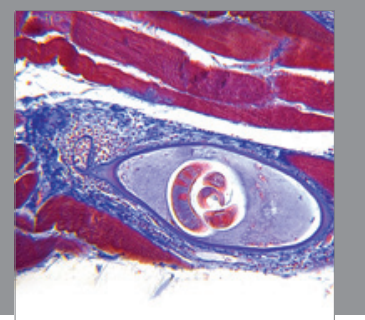

Gastroenterology

Research and Practice
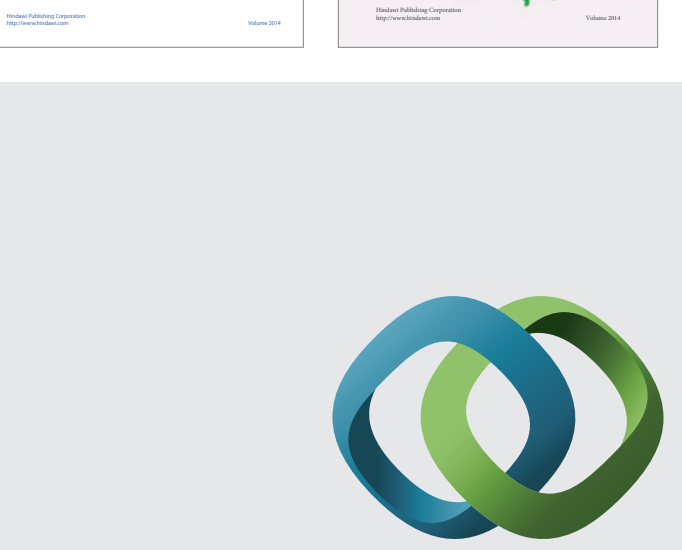

\section{Hindawi}

Submit your manuscripts at

http://www.hindawi.com
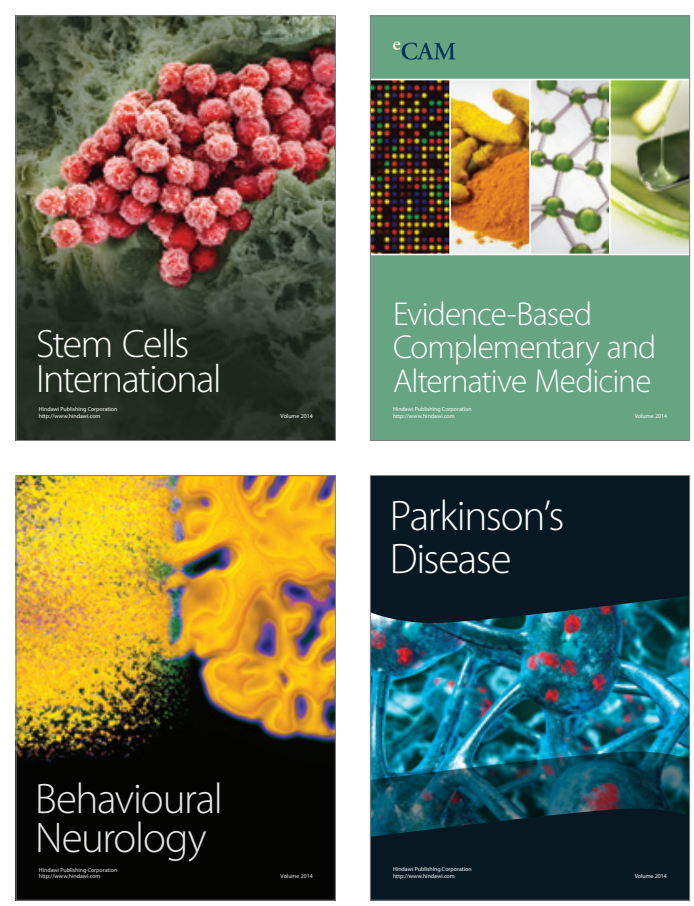

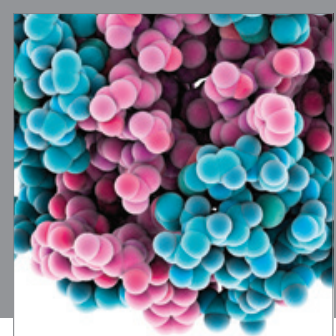

Journal of
Diabetes Research

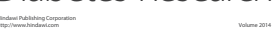

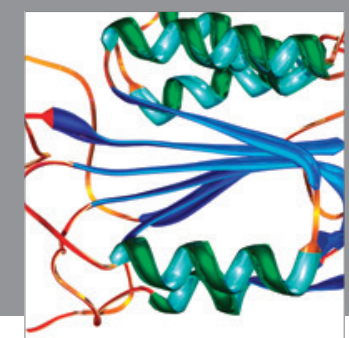

Disease Markers
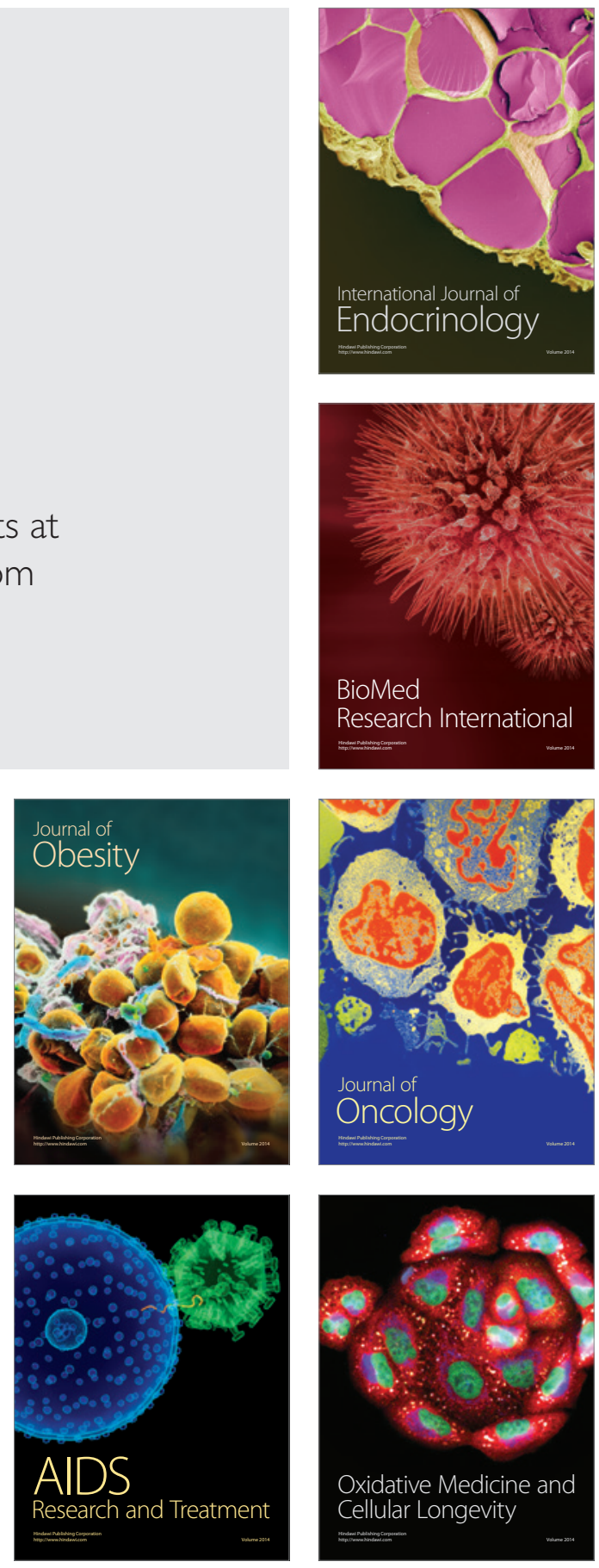